\title{
Long-Term Environmental Policy
}

Challenges for Research

Suggested citation referring to the original publication:

The journal of environment \& development, 21(1), 2012, pp. 67-70

DOI http://dx.doi.org/10.1177/1070496511435667

ISSN (print) 1070-4965

ISSN (online) 1552-5465

Postprint archived at the Institutional Repository of the Potsdam University in:

Postprints der Universität Potsdam

Wirtschafts- und Sozialwissenschaftliche Reihe ; 81

ISSN 1867-5808

http://nbn-resolving.de/urn:nbn:de:kobv:517-opus4-403193 



\title{
Long-Term \\ Environmental Policy: \\ Challenges for Research
}

The Journal of Environment \& Development

21 ( I) 67-70

(C) 2012 SAGE Publications

Reprints and permission: sagepub.com/journalsPermissions.nav DOI: 10.1 | $77 / 10704965$ | |435667 http://jed.sagepub.com

@SAGE

\section{Detlef F. Sprinz ${ }^{1,2}$}

\begin{abstract}
Long-term policy issues are a particularly vexing class of environmental policy issues which merit increasing attention due to the long-time horizons involved, the incongruity with political cycles, and the challenges for collective action. Following the definition of long-term environmental policy challenges, I pose three questions as challenges for future research, namely I. Are present democracies well suited to cope with long-term policy challenges? 2. Are top-down or bottom-up solutions to long-term environmental policy challenges advisable? 3. Will mitigation and adaptation of environmental challenges suffice? In concluding, the contribution raises the issue of credible commitment for long-term policy issues and potential design options.
\end{abstract}

\section{Keywords}

anniversary issue, long-term policy, definition, design options, environmental policy

For years, European governments have been grappling with the challenge whether they will honor their commitments to repay the public debts they have accumulated since the second half of the 20th century. The central challenge has been to shore up confidence among investors that they are indeed able and willing to repay their debts. In the environmental field, we face an even more demanding challenge: Can we repair environmental damages that have sometimes been accumulating over centuries, and prevent the creation of adverse, long-term environmental outcomes? I coin this class of environmental issues to be "long-term policy challenges." In the following, I will

'Potsdam Institute for Climate Impact Research, Potsdam, Germany

${ }^{2}$ University of Potsdam, Germany, Potsdam, Germany

\section{Corresponding Author:}

Detlef F. Sprinz, Potsdam Institute for Climate Impact Research, P. O. Box 6012 03, Potsdam I44I2,

Germany

Email: dsp@pik-potsdam.de

*Sustainable Development from Rio 1992 to Rio 2012 and Beyond:Taking stock and moving forward. This article was written by invitation as a contribution to the $20^{\text {th }}$ anniversary issue of the Journal of Environment and Development, March 2012 
briefly define and illustrate them, pose some pertinent research questions, and conclude with suggestions on how to address and (hopefully) cope with them.

Long-term policy challenges are defined as "public policy issues that last at least one human generation, exhibit deep uncertainty exacerbated by the depth of time, and engender public goods aspects both at the stage of problem generation as well as at the response stage" (Sprinz, 2009, p. 2). Let me illustrate this definition with the help of three examples. First, overfishing in parts of the North Atlantic has substantially depleted fishery stocks, and even closing off some of these sites for decades has not lead to full recovery. Climate change and species extinction definitely exceed one quarter century of impacts. Second, in all three cases, the depth of time needed for recovery is particularly long, and it remains unclear whether core relationships in our present analyses will remain constant over time-except for species extinctionwhich is forever. Third, all these environmental problems were created by not taking account of the side-effects of human actions, such as burning fossil fuels. There have been smaller or larger "tragedies of the commons" (Garrett Hardin) in the making by creating negative externalities. And there is rarely a universal rush to curb such problems due to the problem of creating coalitions for collective action on a regional or global scale. Although only a subset of environmental problems qualifies as long-term policy challenges, those cases which do fulfill the definitional requirements are of a particular difficult nature to cope with.

Until now, research and public policy have only inadequately addressed long-term policy challenges. Conversely, this affords present and future scholars with an opportunity to address pertinent research questions. ${ }^{1}$ For brevity, I will outline preliminary ideas to three challenges:

1. Are present democracies well suited to cope with long-term policy challenges?

2. Are top-down or bottom-up solutions to long-term environmental policy challenges advisable?

3. Will mitigation and adaptation of environmental challenges suffice?

Let me briefly elaborate each of these challenges.

First, electoral cycles of 4 to 5 years are not necessarily the ideal solution to cope with problems which easily encompass whole political or administrative careers to successfully manage them. It is the relationship between the relatively fast electoral clock and the comparatively slow clock of long-term policy environmental policy challenges which poses the question of institutional design to master asynchronous clocks.

Second, are top-down or bottom-up solutions to long-term environmental policy challenges advisable? This issue is hotly debated especially, in the area of climate change policy. The hopes for a global agreement to succeed the Kyoto Protocol to the UN Framework Convention on Climate Change have been dashed in late 2009 at Copenhagen. Global agreements with strong obligations and convincing sanctions in 
case of noncompliance would be desirable, but have hitherto not been concluded. Much like a (double-faced) sandwich, I anticipate that we will have to suitably combine top-down and bottom-up approaches to create an effective "sandwich solution" to climate change and other long-term environmental policy challenges in the absence of stringent and enforceable global agreements. This will require the distribution of functional tasks across the various parts of the sandwich (Sprinz, 2010).

Third, much of environmental policy builds on mitigation (lessening of causes) and adaptation (lessening of effects). What is often missing is an important third component, namely compensation. Not all environmental impacts can be avoided, especially, if it takes a human generation or longer to return to the status quo ante. This suggests that long-term, adverse impacts should be compensated for in a systematic, nonarbitrary way. We will need a specialized judiciary to cope with the impacts of climate change or loss of biodiversity, both at the national and the international levels. In addition to such an independent judiciary, potential awards have to be backed up by adequate funds (Sprinz \& von Bünau, 2011).

This leaves us with the question whether governments and other agents can credibly commit to limit long-term environmental change in a decentralized world. Credibility implies that one normally does not renege on one's earlier promises, except for unforeseeable circumstances. Unambitious policy paths essentially avoid the credible commitment (or time inconsistency) challenge. Conversely, how can environmental stewards be bound to the mast of their Earthship, their ears plugged with wax (referring to Odysseus in the epic Homer), and their eyes kept out of sight of other distractions? The short answer is that it will not be easy, yet there is no reason to despair. We will have to design policy instruments that allow for credible commitment by delegation of authority (e.g., carbon banks removed from daily politics), laws that are not easily changed (high threshold for majorities to revert decisions), clever financial instruments (that allow the investor in research and development to participate in the fruits of successful ventures rather than outright losses due to unconditional subsidies), price guarantees (e.g., minimum price for carbon offsets), sunset policies (for harmful activities), and transparency (about the consequences of harmful and benign policies; Sprinz, in press). Perhaps most important, we need a politically independent research sector that informs the mass public and policy-makers of successful policies and the lack thereof.

\section{Declaration of Conflicting Interests}

The author declared no potential conflicts of interest with respect to the research, authorship, and/or publication of this article.

\section{Funding}

The author received no financial support for the research, authorship, and/or publication of this article. 


\section{Note}

1. For a more elaborate development of these arguments, see Sprinz (2009).

\section{References}

Sprinz, D. F. (2009). Long-term environmental policy: Definition, knowledge, future research. Global Environmental Politics, 9(3), 1-8.

Sprinz, D. F. (2010). The "sandwich solution" to global climate policy. In Delivering tomorrow: Towards sustainable logistics (pp. 71-74). Bonn, Germany: Deutsche Post AG.

Sprinz, D. F. (in press). Long-term environmental policy: Definitions-origin-response options. In P. Dauvergne (Ed.), Handbook of global environmental politics (2nd ed.). Cheltenham, MA: Edward Elgar.

Sprinz, D. F. \& S. von Bünau. (2011). The Climate compensation fund for climate impacts. Retrieved from http:/www.uio.no/english/research/interfaculty-research-areas/milen/ events/Sprinz.CCP.23August2011.pdf

\section{Bio}

Detlef F. Sprinz is a Senior Scientist with the Research Domain "Transdisciplinary Concepts \& Methods" of PIK - Potsdam Institute for Climate Impact Research, a Professor with the Faculty of Economic and Social Sciences at the University of Potsdam, Germany, and Chairman of the Scientific Committee of the European Environment Agency, Copenhagen. His areas of research and publications encompass long-term policy, inter/national institutions \& the evaluation of their performance, European \& international environmental policy, and modeling political decisions. He is the guest editor of the special issue of Global Environmental Politics on "Long-term Environmental Policy" (August 2009), co-editor of International Relations and Global Climate Change (The MIT Press, 2001; second edition in progress), and of Models, Numbers, and Cases: Methods for Studying International Relations (The University of Michigan Press, 2004) in addition to numerous journal articles. 